\title{
Clinical and microbiological characteristics of corneal ulcers in a Thai referral center
}

\author{
Kosol Kampitak, Haruetai Suntisetsin, Tasanee Sirikul \\ Department of Ophthalmology, Faculty of Medicine, Thammasat University, Pathumthani 12120, \\ Thailand
}

\begin{abstract}
Background: There are regional variations in causative organisms and epidemiologic patterns of corneal ulcers. It is essential to review periodically in terms of epidemiology and the microbial keratitis profiles that occur in a specific region in order to develop a comprehensive strategy for diagnosis and management of corneal ulcers.

Objective: To review the epidemiology, predisposing factors, microbiological characteristics and visual outcomes in corneal ulcers at a referral center in Thailand.

Methods: A retrospective review of patients with clinically diagnosed corneal ulcers presenting between January 2006 and December 2010 was performed.

Results: A total of 159 patients (159 eyes) were analyzed. Ninety-one cases (57.2\%) were in men. The mean age of the patients was $43.0 \pm 20.0$ years. The most common predisposing factor was ocular trauma found in 72 eyes (45\%). Culture was grown from 123 eyes and results were positive in 52\%. The most frequent causative organisms were bacteria $(72 \%)$, followed by fungus $(28 \%)$. The most common bacteria was Pseudomonas aeruginosa $(55 \%)$ and most common fungus was Fusarium species (33\%). In a comparison between fungal and bacterial groups, the latter was more likely to be associated with contact lens wear $(p=0.05)$. The hospitalization time for the fungal group was significantly longer than for the bacterial group $(p=0.001)$. The posttreatment corrected visual acuity equal to or better than 20/200 was found significantly more commonly in the bacterial group than in the fungal group $(p=0.031)$. While therapeutic keratoplasty was significantly higher in the fungal group than in the bacterial group $(p=0.048)$.

Conclusion: Fungal keratitis was more severe than bacterial keratitis resulting in longer hospitalization time, poorer visual acuity, and with more chance to have therapeutic keratoplasty.
\end{abstract}

Keywords: Corneal ulcers, epidemiology, organisms, predisposing factors, visual outcomes

Corneal ulcer is a common infectious disease that is potentially blinding in clinical practice. There are regional variations in causative organisms and epidemiological patterns depending on different patient populations, occupational risk factors, and climate. Several studies from different regions or different times in Thailand have addressed these issues [1-7]. In developing countries, the most common predisposing factor was ocular trauma [8-11] while in developed countries, it was found that contact lens wear could be a more common cause [12-14]. Common organisms were bacteria and fungus. Severe corneal ulcers might progress to corneal perforation, with poor visual outcome, and possible evisceration. Identification of the pathogens and appropriate

Correspondence to: Kosol Kampitak, MD, Department of Ophthalmology, Faculty of Medicine, Thammasat University, Pathumthani 12120, Thailand. E-mail: kosolkampitak@ yahoo.com treatment is critical to a good clinical outcome, nevertheless there was a variance in the rate of positive culture in referral centers of Thailand [1-7]. Thus, it is essential to review periodically in terms of epidemiology and the microbial keratitis profiles that occur in a specific region in order to develop a comprehensive strategy for diagnosis and management of corneal ulcer.

The purpose of this study was to determine epidemiologic characteristics, microbiological profiles, predisposing factors, and visual outcomes at Thammasat Hospital, which is a referral center in Thailand where the majority of the population are agricultural and industrial workers.

\section{Materials and methods}

A retrospective review of 159 case of corneal ulcer in Thammasat Hospital, over a period of 5 years from January 2006 to December 2010, was conducted 
from medical records. Keratitis from viral infection was excluded from this study. Demographic data, predisposing factors, microbiological profile, hospitalization time, pretreatment and posttreatment visual acuity using a pinhole with Snellen letter charts were reviewed. Predisposing factors were classified into ocular trauma, contact lens wear, ocular surface diseases, and associated systemic diseases.

Results were analyzed using a $t$ test used for quantitative data and Pearson's Chi-square test (expected count more than 5) or Fisher's exact test (expected count less than 5) for qualitative data at $95 \%$ confidence intervals.

This research was approved by the Ethics Committee at Thammasat University, Thailand (research code MTU-OP-1-CR091-091/53). We certify that all applicable institutional and governmental regulations concerning the ethical use of human volunteers were followed during this research and that it adhered to the tenets of the Declaration of Helsinki.

\section{Results \\ Demographics}

There were 159 case of corneal ulcer (159 eyes) in the 5 years from January 2006 to December 2010. Ninety-one cases $(57.2 \%)$ were in men and 68 cases $(42.8 \%)$ were in women. The ratio of men to women was 1.3:1. The mean age and standard deviation was 43.020 .0 years, range from 3 to 91 years. The most common age range was $21-30$ years $(30 / 159,18.9 \%)$, followed by $31-40$ years $(29 / 159,18.2 \%)$, as shown in Figure 1. There was no significant difference between the mean age in men (44.4 \pm 19.7 years) and women ( $41.0 \pm 20.2$ years $), p=0.28$. The mean age and standard deviation in patients with contact lens related disease was $25.6 \pm 6.4$, which was younger than in patients with microbial keratitis secondary to the other factors. Patients with histories of ocular trauma, ocular surface diseases, and systemic diseases had a mean age of $42.1 \pm 18.6$ years, $61.0 \pm 16.1$ years, and $61.9 \pm 14.2$ years, respectively.

\section{Clinical characteristics and predisposing factors}

One hundred and thirty six (86\%) patients were admitted to hospital, while the others were treated in an outpatient clinic. The mean hospitalization time and standard deviation was $16.6 \pm 14.2$ days, with a range of 1-67 days. In fungal keratitis, the mean hospitalization time (29.7 \pm 19.1 days) was significantly longer than for bacterial keratitis (14.0 \pm 10.4 days), $p=0.001$. Predisposing factors were reported in $129(81 \%)$ eyes. Some patients had more than 1 predisposing factor. Ocular trauma was the most common predisposing factor of infection $(72,45 \%)$ followed by contact lens wear $(35,22 \%)$, ocular surface diseases $(18,11 \%)$, and systemic diseases (17, $11 \%)$. The was no predisposing evidence in 30 cases $(19 \%)$. Ocular trauma was significantly more common in males than in females $(p<0.001)$, whereas contact lens wear was significantly more common among women than men $(p<0.001)$ (Table 1). Ocular surface diseases caused by lid or lash abnormality $33 \%$ (6/18), bullous keratopathy $22 \%$ (4/18), neurotrophic keratopathy $22 \%(4 / 18)$, severe dry eye $17 \%(3 / 18)$, and corneal dystrophy $6 \%(1 / 18)$. Systemic disease consisted of diabetes mellitus $82 \%(14 / 17)$, human immunodeficiency virus infection $12 \%(2 / 17)$, and systemic lupus erythematosus $6 \%(1 / 17)$.

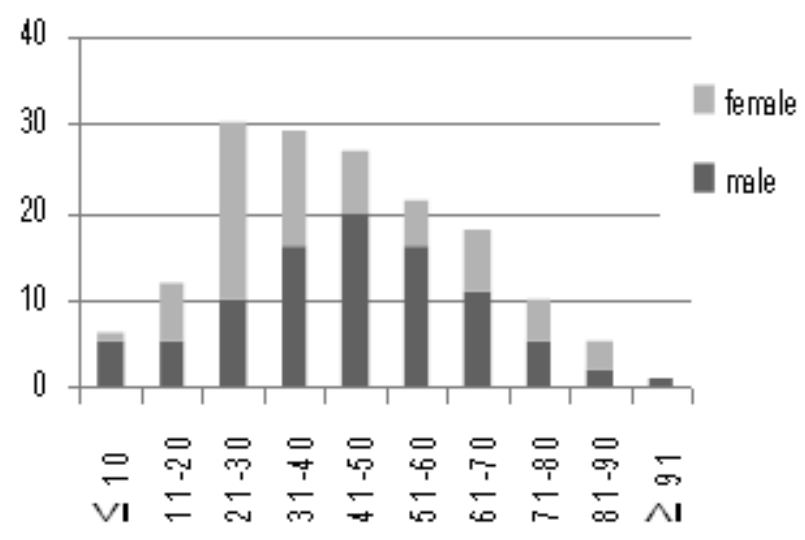

Age group (years)

Figure 1. Proportion of corneal ulcer cases distributed by age group and sex 
Table 1. Predisposing factors associated with cases of corneal ulcer

\begin{tabular}{|c|c|c|c|c|}
\hline \multirow[b]{2}{*}{ Predisposing factors } & \multicolumn{3}{|c|}{ n (\%) } & \multirow[b]{2}{*}{$p^{\mathrm{a}}$} \\
\hline & $\begin{array}{c}\text { Total } \\
\text { (n = } 159 \text { eyes) }\end{array}$ & $\begin{array}{c}\text { Men } \\
\text { ( } n=91 \text { eyes) }\end{array}$ & $\begin{array}{c}\text { Women } \\
(n=68 \text { eyes })\end{array}$ & \\
\hline Ocular trauma & $72(45)$ & $55(60)$ & $17(25)$ & $<0.001$ \\
\hline Contact lens wear & $35(22)$ & $5(6)$ & $30(44)$ & $<0.001$ \\
\hline Ocular surface diseases & $18(11)$ & $7(7)$ & $11(16)$ & 0.16 \\
\hline Systemic diseases & $17(11)$ & $9(10)$ & $8(12)$ & 0.91 \\
\hline No predisposing factor & $30(19)$ & $20(22)$ & $10(15)$ & 0.34 \\
\hline
\end{tabular}

$\mathrm{a}=$ Pearson's Chi-square test, there were patients who had more than 1 predisposing factor

Comparing cases where culture was positive, the mean age of the patients with bacterial infection was $40.0 \pm 18.4$ years and patients with fungal infection was $54.7 \pm 13.1$ years, which was significantly different $(p=0.003)$. Contact lens wear was more likely to be associated with bacterial infection than fungal infection $(p=0.05)$.

Pretreatment pinhole visual acuity was equivalent to $20 / 40$ or better in $18 \%(28 / 159), 20 / 70$ to $20 / 200$ in $24 \%(38 / 159)$, worse than $20 / 200$ in $56 \%(89 / 159)$, and no light perception in 3\% (4/159). Posttreatment pinhole visual acuity was equivalent to $20 / 40$ or better in $45 \%$ (71/159), $20 / 70$ to $20 / 200$ in $25 \%$ (40/159), worse than $20 / 200$ in $20 \%(32 / 59)$, and no light perception in $10 \%(16 / 159)$. Compared with fungal keratitis, bacterial keratitis was more likely to be associated with visual outcomes equal to or better than 20/200 ( $p=0.031)$ (Table 2).

One-third of the patients (30\%) had received prior antibacterial therapy. Patients who had received prior antibiotic treatment were more likely to be found in the fungal group than in the bacterial group $(p=0.033)$. Therapeutic or tectonic penetrating keratoplasty was performed in 18 cases $(11 \%)$ and lamella keratoplasty in 1 case $(0.6 \%)$. Evisceration or enucleation was performed in 12 cases ( $8 \%$ ). In the culture-proven group, keratoplasty was more performed significantly more frequently in the fungal keratitis group $(4 / 18$, $22 \%)$ than in the bacterial keratitis group $(2 / 46,4 \%)$, $p=0.048$ (Table 2).

Table 2. Multivariate analysis of clinical characteristics and predisposing factor in bacterial and fungal keratitis

\begin{tabular}{lccc}
\hline & \multicolumn{2}{c}{$\mathbf{n}(\%)$} & \\
\cline { 2 - 3 } & Bacteria (n= 46 eyes) & Fungus (n=18 eyes) & p \\
\hline Pretreatment VA* $\geq 20 / 200$ & $18(39)$ & $5(28)$ & $0.58^{\mathrm{a}}$ \\
Posttreatment VA* $\geq 20 / 200$ & $33(72)$ & $7(39)$ & $0.03^{\mathrm{a}}$ \\
Prior antibacterial therapy & $11(24)$ & $10(56)$ & $0.03^{\mathrm{a}}$ \\
Ocular trauma & $20(44)$ & $10(56)$ & $0.55^{\mathrm{a}}$ \\
Contact lens wear & $10(22)$ & $0(0.0)$ & $0.05^{\mathrm{b}}$ \\
Ocular surface diseases & $6(13)$ & $1(6)$ & $0.66^{\mathrm{b}}$ \\
Systemic diseases & $6(13)$ & $4(22)$ & $0.45^{\mathrm{b}}$ \\
Keratoplasty & $2(4)$ & $4(22)$ & $0.048^{\mathrm{b}}$ \\
Evisceration/enucleation & $3(7)$ & $4(22)$ & $0.09^{\mathrm{b}}$ \\
& & $(\mathrm{Mean} \pm \mathrm{SD})$ & $\left(\mathrm{Mean}^{\mathrm{a}} \pm \mathrm{SD}\right)$ \\
Age (years) & $40.0 \pm 18.4$ & $54.7 \pm 13.1$ & $0.003^{\mathrm{c}}$ \\
Admission duration (days) & $14.0 \pm 10.4$ & $29.7 \pm 19.1$ & $0.001^{\mathrm{c}}$ \\
\hline
\end{tabular}

*VA = visual acuity, $\mathrm{a}=$ Pearson's Chi-square test, $\mathrm{b}=$ Fisher's exact test, $\mathrm{c}=t$ test 


\section{Microbiological profile}

Corneal scraping and culture were performed in 123 cases. Positive culture results occurred in $52 \%(64 / 123)$. The most frequent causative organism was bacteria $72 \%(46 / 64)$, followed by fungus $28 \%(18 / 64)$. There was 1 eye that had mixed organisms of bacteria. Bacterial organisms included 10 Gram-positive isolates $(21.3 \%), 35$ Gramnegative isolates $(74.5 \%)$, and 2 of actinomycetes (4.3\%). Pseudomonas aeruginosa was the most common bacteria accounting for 55\% (26/47) of all isolated bacteria, followed by coagulase-negative staphylococcus 11\% (5/47) (Table 3). Fusarium species was the most common fungal organism 33\% (6/18), followed by Aspergillus species 28\% (5/18) (Table 4).

In the total 35 cases in contact lens wearers, $29 \%$ $(10 / 35)$ of cultures from corneal scraping were positive. Nine out of 10 cases were Pseudomonas aeruginosa and only one case was Acinetobacter baumannii. There was no fungal growth from the eyes of contact lens-wearing patients in this study.

Table 3. Bacteria isolated and relative frequencies

\begin{tabular}{|c|c|c|}
\hline Name of Bacteria & $\begin{array}{l}\text { No. isolates } \\
(\mathbf{n}=47)^{*}\end{array}$ & $\%$ \\
\hline \multicolumn{3}{|l|}{ Gram-positive cocci } \\
\hline Coagulase-negative staphylococci & 5 & 11 \\
\hline Staphylococcus aureus & 1 & 2 \\
\hline$\beta$-Hemolytic Streptococcus & 1 & 2 \\
\hline \multicolumn{3}{|l|}{ Gram-positive bacilli } \\
\hline Bacillus species & 1 & 2 \\
\hline Corynebacterium species & 1 & 2 \\
\hline Other gram-positive aerobic bacilli & 1 & 2 \\
\hline \multicolumn{3}{|l|}{ Gram-negative bacilli } \\
\hline Pseudomonas aeruginosa & 26 & 55 \\
\hline Pseudomonas stutzeri & 2 & 4 \\
\hline Acinetobacter baumannii & 1 & 2 \\
\hline Enterobacter cloacae & 1 & 2 \\
\hline Haemophilus influenzae & 1 & 2 \\
\hline Klebsiella species & 1 & 2 \\
\hline Morganella morganii & 1 & 2 \\
\hline Proteus mirabilis & 1 & 2 \\
\hline Other gram-negative aerobic bacilli & 1 & 2 \\
\hline \multicolumn{3}{|l|}{ Aerobic actinomycetes } \\
\hline Nocardia species & 1 & 2 \\
\hline Mycobacterium species & 1 & 2 \\
\hline \multicolumn{3}{|c|}{$\begin{array}{l}\text { * Total } 46 \text { eyes, } 1 \text { eye had mixed organisms of Pseudomonas stutzeri and coagulase-negative } \\
\text { staphylococcus }\end{array}$} \\
\hline \multicolumn{3}{|c|}{ Table 4. Fungal isolated and relative frequencies } \\
\hline Fungus names & $\begin{array}{l}\text { No. isolates } \\
(\mathbf{n}=\mathbf{1 8})\end{array}$ & $\%$ \\
\hline \multicolumn{3}{|l|}{ Filamentous fungi } \\
\hline Hyaline fungi (nonpigmented hyphae) & 6 & 33 \\
\hline Fusarium species & 5 & 28 \\
\hline Aspergillus species & 3 & 17 \\
\hline \multicolumn{3}{|l|}{ Unclassified hyaline fungi } \\
\hline Dematiaceous fungi (pigmented hyphae) & 1 & 6 \\
\hline Curvularia species & 1 & 6 \\
\hline Unclassified dematiaceous fungi & & \\
\hline \multicolumn{3}{|l|}{ Yeast } \\
\hline Candida glabrata & 1 & 6 \\
\hline Unclassified yeast species & 1 & 6 \\
\hline
\end{tabular}




\section{Discussion}

This study has reported on all age groups, ranging from 3 to 91 years. The most common age range was $21-30$ years $(19 \%)$, followed by $31-40$ years $(18 \%)$. These age groups were of working age and thus might have more chance to suffer ocular trauma or use contact lens. The age distribution for microbial keratitis is associated with the contributing risk factors. Our patients with contact lens-related keratitis had a mean age of 25.6 years and those with associated ocular disease and systemic disease-related keratitis had a mean age of 61.0 and 61.9 years, respectively. We found that patients with contact lens-related disease were younger than patients with microbial keratitis that was secondary to other factors. Associated ocular disease and systemic disease related keratitis were found mostly in the elderly, which is consistent with other reports $[6,11,12,15,16]$.

This study found that the mean age of the bacterial group was 40.0 years, which was significantly $(p=0.003)$ younger than for the fungal group (54.7 years). This may be explained by contact lens wear, which was found to be a common risk factor in bacterial keratitis and the mean age of the contact lens wearing patients was younger than the others.

Our study had a higher ratio of men to women, which was similar to other studies undertaken in Thailand [1-7] and several other countries [8-10]. This is probably because ocular trauma was the main risk factor in our study and ocular trauma was found to be significantly more common in men than in women $(p<0.001)$. Like the study by Keay et al. in Australia study, the ocular trauma group was found to be $91 \%$ male, and this trauma was significantly more common in men than in women $(p<0.001)$ [15]. However, the study by Ibrahim et al. [12] in England found the percentage of women to be slightly higher than that of men. This might be because wearing contact lenses was most common risk factor in that study and $63.7 \%$ of contact lens wearers were women. Similarly, in our study there were significantly more female contact lens wearers than men $(p<0.001)$.

Ocular trauma has been identified as the most common risk factor for microbial keratitis in this study, similar to other studies in Thailand [1-7] and many developing countries [8-11]. Whereas, in developed countries some studies found that wearing contact lenses was the most common predisposing factor, such as in England [12], Australia [13], and Japan [14]. The study by Ibrahim et al. in England found that wearing contact lenses was the main risk factor $(31 \%)$. Other risk factors included ocular diseases (23.7\%), ocular trauma (6.4\%), and systemic diseases (4.7\%) [12]. The study by Green et al. in Australia found that predisposing factors were wearing contact lenses $22 \%$, ocular disease $18 \%$, ocular trauma $16 \%$, and previous ocular surgery $11 \%$ [13].The study by Toshida et al. in Japan, found that contact lens wear was the main risk factor $(54.5 \%)$, and ocular surface disease and previous ocular surgery were present in $20.5 \%$ and $13.1 \%$ of cases, respectively [14].

From the current study, the contact lens wearers had a significantly higher chance of bacterial infection than fungal infection $(p=0.05)$. This finding is consistent with report of Sirikul et al. [7], which showed that fungal keratitis was less likely to be associated with contact lens wear.

The proportion of positive culture was different in each report, ranging from $30 \%$ to $79 \%$ [3-6, 8-13]. Positive microbial growth has been identified in 52\% of corneal scrapes in our study, which was comparable with other studies from referral centers in Thailand, such as Siriraj hospital (51\%) [3] and Chulalongkorn hospital (47\%) [5].

The causative organisms in this study were bacteria and fungus. Positive cultures were bacteria in 46 cases $(46 / 64,72 \%)$ and fungus in 18 cases (18/ $64,28 \%$ ). This was similar to other studies that found bacteria, rather than fungus. For example, in India bacteria was found in $22 \%$ of cases, fungus in $19.7 \%$, and mixed organisms including bacteria and fungus $14 \%$ and Acanthamoeba 1.1\% [8]. Studies in Bangkok from Siriraj Hospital found bacteria in 53\% of cases and fungus in 25\% [3], King Chulalongkorn Memorial Hospital found bacteria in $32.5 \%$ of cases and fungus in $11.6 \%$ [5], Ramathibodi Hospital found bacteria in $60 \%$ of cases, fungus in $38 \%$, and Acanthamoeba in 2\% [7]. Compared with studies from various other regions of Thailand, such as Khon Kaen (northeast Thailand), which found bacteria in $39 \%$ of cases and fungus in $23 \%$ [1], Chiang Mai (northern Thailand), which found bacteria in $60 \%$ of cases and fungus in 40\% [6], and Songkhla (southern Thailand), which found bacteria in $65.4 \%$ of cases and fungus in $25.9 \%$ [4]. While some studies found fungus rather than bacteria to be the most prevalent cause. For example, in Nepal [17], and Brazil [9], causative organisms were found to be fungus in $61 \%$ and $56.3 \%$ of cases, respectively. By contrast, in developed countries, fungus was less frequently 
found than bacteria. For example, in Australia, fungus was found in only $3 \%$ of cases [13]. In developing countries, ocular trauma was the most common predisposing factor [1-10], but in developed countries the most common predisposing factor was wearing contact lenses [12-14], which was not usually associated with fungal infections [7].

In this study, the most common bacterial isolate was Pseudomonas aeruginosa (55\%), which is similar to findings in other studies in Thailand [1, 3-7] and in Australia [13]. Pseudomonas aeruginosa infection was very common, especially in contact lens wearing patients [13, 18-21]. This study also found that $90 \%(9 / 10)$ of the patients who used contact lenses and had a positive culture for Pseudomonas aeruginosa. Compared with other studies, especially those by Green et al. [13] and Bharathi et al. [19], Pseudomonas aeruginosa was found in the contact lens wearing group of patients at $55 \%$ and $71.4 \%$ respectively, which was significantly $(p<0.001)$ different from other organisms in both reports. Stapleton and Carnt reported that Pseudomonas aeruginosa is the commonest organism of contact lens-related corneal infection, probably because of its unique virulence characteristics and ability to survive in the contact lens, storage case, and ocular environment [22]. However, some studies showed that Gram-positive bacteria were the most common causative bacterial organism. For example, the study by Orlans et al. in England, found that the most commonly isolated bacteria were Staphylococci (40.1\%) [23]. Another study in England, by Ibrahim et al., similarly found Gram-positive bacteria, $71.1 \%$ of which were Staphylococcus epidermidis as the most common organism (31.7\%) [12]. The study by Basak et al. in eastern India found that the most common bacteria were Staphylococcus aureus $(42.6 \%)$ [24]. By contrast, some studies revealed Streptococcus pneumoniae as the most common organism. For example, in the study by Bharathi et al. in India [25] and Feilmeier et al. in Nepal [17], found Streptococcus pneumoniae in $69 \%$ and $36.0 \%$ of cases, respectively. The causative organism might depend on what predisposing factor was found. For example, Pseudomonas aeruginosa was usually found in contact lens wearing patients [13, 18-21]. Staphylococcus aureus was more common in ocular surgery-related patients [13]. Whereas, fungus was commonly found in patients with ocular trauma $[7,25]$.
In most studies, Fusarium species and Aspergillus species were the most common fungal organisms [26]. In this study, Fusarium species was the most common organism (33\%), followed by Aspergillus species (28\%). This is consistent with other studies in Thailand [4-7], Brazil [9], Australia [13], and southern India [25], which found that Fusarium species was the most common fungal organism. However, some studies, such that by Basak et al., found Aspergillus species was the most common fungus [24]. This study in eastern India found that Aspergillus species was the most common fungus (59.8\%), followed by Fusarium species $(21.2 \%)$. The study by Feilmeier et al. in Nepal [17], found Aspergillus species in $35 \%$ of cases, and Fusarium species in $12 \%$. The difference found might be the result of a difference in geography and climate [25].

From this study, the causative organism that was isolated from patients who had previously received antibacterial treatment was significantly $(p=0.033)$ more likely to be from the fungal group $(56 \%, 10 / 18)$ than the bacterial group $(23.9 \%, 11 / 46)$. This might be because Thammasat Hospital is a referral center. Patients with bacterial infections usually respond to antibiotics so they were not referred to Thammasat Hospital. However, with fungal infections, initially patients often had received antibiotics, but had no response to the treatment, so they were referred to Thammasat hospital. Therefore the culture would have had the opportunity to be a fungal.

Some patients in this study were admitted to hospital for up to 67 days. From the study of Sirikul, the admission duration was up to 127 days [7]. Tananuvat et al. found that the admission duration of more than one month was $15.5 \%$ [6]. The longer admission duration was related to the higher cost of treatment [27]. In a comparison between the fungal and bacterial groups, from this study, patients from the fungal group (30 \pm 19 days) had a significantly $(p=0.001)$ longer admission duration than the bacterial group (14 \pm 10 days). This may result from the drug response for fungus being slower than for bacteria or more chance of surgical intervention in fungal group.

Most patients in this study had better visual acuity after treatment. Best corrected visual acuity was equal or more than $20 / 40$ increasing from $17 \%(28 / 159)$ to $45 \%(71 / 159)$, and best corrected visual acuity less than $20 / 200$ decreased from $59 \%(93 / 159)$ to $30 \%$ $(48 / 159)$ after treatment. While patient with no light perception increased by $7 \%$ (12/159). Compared 
with other studies, Tananuvat et al. found that posttreatment best corrected visual acuity improved equally or by more than 1 row was $59.4 \%$, unchanged $13.6 \%$, and worse $14.5 \%[6]$. The study by Furlanetto et al. found that final visual acuity was equally or better than $20 / 60$ in $30.8 \%$, between $20 / 60$ and $20 / 400$ in $10.8 \%$, and worse than $20 / 400$ in $53.9 \%$ [9]. Most corneal ulcers would be even better after treatment, but there were those who lost their sight. This report found that patients in the bacterial group had better treatment outcomes than the fungal group. Posttreatment best corrected visual acuity equal or more than $20 / 200$ in the bacterial group patients $(71.7 \%, 33 / 46)$ was significantly $(p=0.031)$ more than for the fungal group $(38.9 \%, 7 / 18)$. This may be the result of the response rate to the drug for the bacterial group better than for the fungal group. Prajna et al. found that predictors for worse 3-month visual acuity in fungal keratitis were older age $(p=0.024)$, worse presentation visual acuity $(p<0.001)$, larger infiltrate size at presentation $(p<0.001)$, and a pigmented ulcer $(p=0.030)$ [28].

Surgical intervention in this study, included therapeutic penetrating keratoplasty or lamella keratoplasty, was $12 \%$. Compared with other studies, Furlanetto et al. [9] and Boonpasart et al. [5] used penetrating keratoplasty in $18.5 \%$ and $34.2 \%$ of cases, respectively. In this study, evisceration or enucleation was performed in $8 \%$ of cases. The proportion of cases that needed evisceration or enucleation in the study by Boonpasart et al. was $25 \%$ [5], in that by Tananuvat et al., 23.2\% [6], and that by Furlanetto et al., 3.08\% [9]. The rate of surgical intervention depended on the severity of disease. Comparing only cases with a positive culture, the current study found that therapeutic penetrating keratoplasty or lamella keratoplasty was performed for the fungal group patients $(22 \%, 4 / 18)$ a significantly higher proportion than for the bacterial group patients $(4 \%, 2 / 46)$ $(p=0.048)$. However, there was no statistically significance for evisceration or enucleation between the groups $(p=0.09)$.

\section{Conclusion}

Corneal ulcers are found in all age groups and both sexes. The most common organisms are bacteria and fungi. Fungal infection was more severe than bacterial infection, resulted in longer hospitalization time, poorer visual acuity, with more chance of keratoplasty being performed. There were some people who lost vision to blindness and some needed evisceration or enucleation. Visual acuity might remain poor even after successful treatment, because of corneal scaring that still obscures vision. This study found that fungal corneal ulcers were more severe than bacterial corneal ulcers resulting in longer hospitalization time, poorer final visual acuity, and with more chance to have therapeutic keratoplasty. Therefore, the patients who had previously received antibacterial therapy and did not respond to the treatment, were likely to have a fungal infection. Moreover, knowledge of how to prevent ocular trauma and proper care for contact lens, which are the two main predisposing factors, may reduce the chances of emerging cases of corneal infection.

\section{Acknowledgments}

This study was funded by the Faculty of Medicine Research Committee, Thammasat University. The authors presented this study at the Royal College of Ophthalmologists Annual Congress Liverpool, May, 2012; United Kingdom. The authors declare no conflicts of interest to this study.

\section{References}

1. Yospaiboon Y, Prabriputaloong A. Ulcerative keratitis: clinical analysis of 183 cases. Ramathibodi Med J. 1986; 9:23-9.

2. Kunavisarut S, Prawinwong K, Sirimongkolkasem A. Corneal ulcer: clinical analysis of 60 cases. Ramathibodi Med J. 1989; 12:122-6.

3. Kosrirukvongs P, Prabhasawat P, Dumavibhat P. Corneal ulcer at Siriraj Hospital. Siriraj Hosp Gaz. 1992; 44:856-67.

4. Kanok-kantapong S, Ratanasukhofl M. Ulcerative keratitis in Songklanagarind Hospital. Thai J Ophthalrnol. 1994; 8:9-16.

5. Boonpasart S, Kasetsuwan N, Puangsricharern V, Pariyakanok L, Jittpoonkusol T. Infectious keratitis at King Chulalongkorn Memorial Hospital: a 12-year retrospective study of 391 cases. J Med Assoc Thai. 2002; 85 Suppl 1:S217-30.

6. Tananuvat N, Sienglew S, Ausayakhun S. Microbial keratitis leading to admission at Maharaj Nakorn Chiang Mai Hospital. Chiang Mai Med Bull. 2004; 43: 93-103.

7. Sirikul T, Prabriputaloong T, Smathivat A, Chuck RS, Vongthongsri A. Predisposing factors and etiologic diagnosis of ulcerative keratitis. Cornea. 2008; 27: 283-7. 
8. Panda A, Satpathy G, Nayak N, Kumar S, Kumar A. Demographic pattern, predisposing factors and management of ulcerative keratitis: evaluation of one thousand unilateral cases at a tertiary care centre. Clin Experiment Ophthalmol. 2007; 35:44-50.

9. Furlanetto RL, Andreo EG, Finotti IG, Arcieri ES, Ferreira MA, Rocha FJ. Epidemiology and etiologic diagnosis of infectious keratitis in Uberlandia, Brazil. Eur J Ophthalmol. 2010; 20:498-503.

10. Laspina F, Samudio M, Cibils D, Ta CN, Farina N, Sanabria R, et al. Epidemiological characteristics of microbiological results on patients with infectious corneal ulcers: a 13-year survey in Paraguay. Graef Arch Clin Exp Ophthalmol. 2004; 242:204-9.

11. Parmar P, Salman A, Kalavathy CM, Kaliamurthy J, Thomas PA, Jesudasan CA. Microbial keratitis at extremes of age. Cornea. 2006; 25:153-8.

12. Ibrahim YW, Boase DL, Cree IA. Epidemiological characteristics, predisposing factors and microbiological profiles of infectious corneal ulcers: the portsmouth corneal ulcer study. Br J Ophthalmol. 2009; 93:1319-24.

13. Green M, Apel A, Stapleton F. Risk factors and causative organisms in microbial keratitis. Cornea. 2008; 27:22-7.

14. Toshida H, Kogure N, Inoue N, Murakami A. Trends in microbial keratitis in Japan. Eye Contact Lens. 2007; 33:70-3.

15. Keay L, Edwards K, Naduvilath T, Taylor HR, Snibson GR, Forde K, et al. Microbial keratitis predisposing factors and morbidity. Ophthalmol. 2006; 113:109-16.

16. Kunimoto DY, Sharma S, Garg P, Gopinathan U, Miller D, Rao GN. Corneal ulceration in the elderly in Hyderabad, south India. Br J Ophthalmol. 2000; 84: 54-9.

17. Feilmeier MR, Sivaraman KR, Oliva M, Tabin GC, Gurung R. Etiologic diagnosis of corneal ulceration at a tertiary eye center in Kathmandu, Nepal. Cornea. 2010;29:1380-5.

18. Sharma S, Gopalakrishnan S, Aasuri MK, Garg P, Rao
GN. Trends in contact lens-associated microbial keratitis in Southern India. Ophthalmol. 2003; 110: 138-43.

19. Bharathi MJ, Ramakrishnan R, Meenakshi R, Kumar CS, Padmavathy S, Mittal S. Ulcerative keratitis associated with contact lens wear. Indian J Ophthalmol. 2007; 55:64-7.

20. Preechawat P, Ratananikom U, Lerdvitayasakul R, Kunavisarut S. Contact lens-related microbial keratitis. J Med Assoc Thai. 2007; 90:737-43.

21. Musa F, Tailor R, Gao A, Hutley E, Rauz S, Scott RAH. Contact lens-related microbial keratitis in deployed British military personnel. Br J Ophthalmol. 2010; 94: 988-93.

22. Stapleton F, Carnt N. Contact lens-related microbial keratitis: how have epidemiology and genetics helped us with pathogenesis and prophylaxis. Eye (Lond). 2012;26:185-93.

23. Orlans HO, Hornby SJ, Bowler IC. In vitro antibiotic susceptibility patterns of bacterial keratitis isolates in Oxford, UK: a 10-year review. Eye (Lond). 2011; 25: 489-93.

24. Basak SK, Basak S, Mohanta A, Bhowmick A. Epidemiological and microbiological diagnosis of suppurative keratitis in Gangetic West Bengal, eastern India. Indian J Ophthalmol. 2005; 53:17-22.

25. Bharathi MJ, Ramakrishnan R, Meenakshi R, Padmavathy S, Shivakumar C, Srinivasan M. Microbial keratitis in South India: influence of risk factors, climate, and geographical variation. Ophthal Epidemiol. 2007; 14:61-9.

26. Thomas PA. Fungal infections of the cornea. Eye (Lond). 2003; 17:852-62.

27. Prajna VN, Nirmalan PK, Saravanan S, Srinivasan M. Economic analysis of corneal ulcers in South India. Cornea. 2007; 26:119-22.

28. Prajna NV, Krishnan T, Mascarenhas J, Srinivasan M, Oldenburg CE, Toutain-Kidd CM, et al. Predictors of outcome in fungal keratitis. Eye (Lond). 2012; 26: 1226-31. 